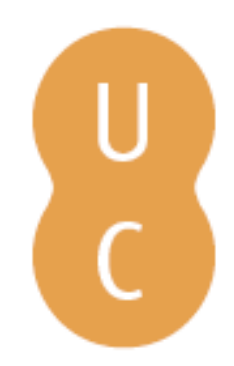

\title{
pommalina
}

\section{Acessibilidade web em ambientes informacionais digitais: 0 olhar da ciência da informação}

\author{
Autor(es): $\quad$ Cusin, Cesar Augusto; Vidotti, Silvana Aparecida Borsetti Gregorio \\ Publicado por: Imprensa da Universidade de Coimbra \\ URL \\ persistente: URI:http://hdl.handle.net/10316.2/31952 \\ DOI: $\quad$ DOI:http://dx.doi.org/10.14195/978-989-26-0869-3_36 \\ Accessed : $\quad$ 26-Apr-2023 15:23:50
}

A navegação consulta e descarregamento dos títulos inseridos nas Bibliotecas Digitais UC Digitalis, UC Pombalina e UC Impactum, pressupõem a aceitação plena e sem reservas dos Termos e Condições de Uso destas Bibliotecas Digitais, disponíveis em https://digitalis.uc.pt/pt-pt/termos.

Conforme exposto nos referidos Termos e Condições de Uso, o descarregamento de títulos de acesso restrito requer uma licença válida de autorização devendo o utilizador aceder ao(s) documento(s) a partir de um endereço de IP da instituição detentora da supramencionada licença.

Ao utilizador é apenas permitido o descarregamento para uso pessoal, pelo que o emprego do(s) título(s) descarregado(s) para outro fim, designadamente comercial, carece de autorização do respetivo autor ou editor da obra.

Na medida em que todas as obras da UC Digitalis se encontram protegidas pelo Código do Direito de Autor e Direitos Conexos e demais legislação aplicável, toda a cópia, parcial ou total, deste documento, nos casos em que é legalmente admitida, deverá conter ou fazer-se acompanhar por este aviso.

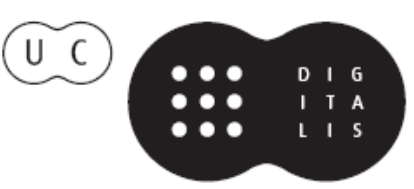


Maria Manuel Borges

Elias Sanz Casado

Coordenação

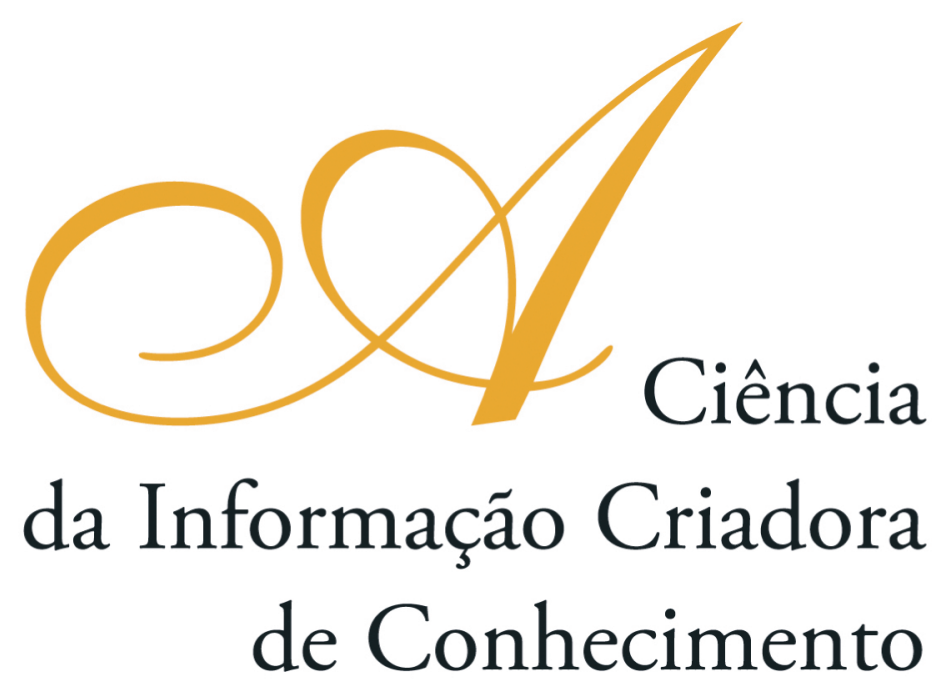

Vol. I I

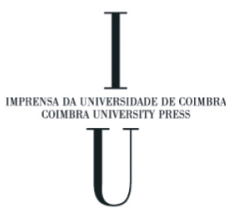

- COImbra 2009 


\section{Acessibilidade Web em Ambientes Informacionais Digitais: o olhar da \\ Cî̂NCIA dA INFORMAÇÃo}

\section{Cesar Augusto Cusin}

Universidade Estadual Paulista (Brasil)

Silvana Aparecida Borsetti Gregorio Vidotti

Universidade Estadual Paulista (Brasil)

\section{Introdução}

A natureza atual da web que destaca a participação colaborativa dos usuários em diversos ambientes informacionais digitais conduz ao desenvolvimento de diretrizes que enfocam a Arquitetura da Informação Digital Inclusiva para diferentes públicos nas mais diversas ambiências informacionais possibilitando a acessibilidade web.

O conceito de acessibilidade web visa a inclusão de usuários com necessidades especiais em ambientes informacionais digitais, com foco na melhoria da interação dos sujeitos com o ambiente de modo a proporcionar a melhoria de qualidade de vida.

\section{Objetivo e Metodologia}

A pesquisa propóe projetar diretrizes para um ambiente informacional digital inclusivo, via revisão bibliográfica, visando apontar os elementos de acessibilidade que permitam a promoção da inclusão informacional digital, de forma a destacar os referenciais da Arquitetura da Informação Digital, de recomendaçôes internacionais e das estruturas de representação das informaçóes, em especial dos metadados de acessibilidade, com o olhar da Ciência da Informação e das novas Tecnologias de Informação e Comunicação.

\section{Desenvolvimento}

O papel do usuário não é simplesmente o de mero espectador da web, o contexto atual é outro, é interativo, é personalizado, é customizado. Nos contextos de interação o usuário tem de fazer um processo de análise e interpretação do conteúdo informacional disponível. Para esse processo possa se efetivar a todos os usuários da web, é necessário que os ambientes informacionais possuam elementos de acessibilidade digital.

Quanto aos aspectos tecnológicos da acessibilidade web, destaca-se o World Wide Web Consortium (W3C), com padróes, recomendaçóes, fazedo parte deste a Web Accessibility Initiative (WAI), que desenvolve estratégias, guias e recursos para tornar a web acessível para usuários com necessidades especiais (Henry, 2007). 
A WAI/W3C, com seus padrôes e guias, é uma parte da equação para o desenvolvimento de ambientes informacionais digitais com acessibilidade. Além dessa, é necessária uma arquitetura da informação preocupada com tal intento e a elaboração de metadados específicos que atendam a descrição dos recursos e a descrição das necessidades dos usuários.

A Arquitetura da Informação (AI) preocupa-se com a estruturação e o planejamento de interfaces digitais, constituindo-se no design do site, design do conteúdo, acessibilidade e usabilidade desses espaços. Para tanto, a AI de Morville e Rosenfeld (2006) resulta da combinação de organização, rotulagem, busca, navegação, tesauro, vocabulário controlado e metadados dentro de websites e das intranets.

Lima-Marques e Macedo (2006) apresentam uma proposta de AI com foco na gestão do conhecimento divida em nível epistemológico, teórico e prático. De Marsico e Levialdi (2004) separam a AI entre representação da informação e aparência, acesso, navegação e organização, e arquitetura do conteúdo informacional.

Com base na premissa de melhor atendimento às necessidades dos usuários, Liddy Nevile, pesquisadora australiana da La Trobe University, vem trabalhando em um framework chamado Access For All (AFA) - Acesso a todos. Basicamente, os metadados AFA destinam-se a identificar recursos que correspondam às preferências e necessidades do usuário (Nevile, 2007).

\section{Consideraçóes}

Quanto aos padróes WAI/W3C, Nevile (2007) apresenta uma pesquisa desenvolvida pela Disabilities Rights Commission apontando que mesmo sites que atendiam aos padróes e guias de acessibilidade não garantiram a acessibilidade ao conteúdo informacional.

Os modelos de AI estudados, Morville e Rosenfeld (2006), Lima-Marques e Macedo (2006) e De Marsico e Levialdi (2004), não abordam efetivamente a acessibilidade digital.

Os metadados AFA esbarram ainda em como descrever as características de acessibilidade dos recursos e ligá-las as necessidades dos usuários.

Assim, configura-se a necessidade de estudos em torno da acessibilidade atrelada a padróes web, AI e metadados visando possibilitar às pessoas com necessidades especiais o acesso, a análise e a interpretação da informação, atendendo assim uma ampla proporção de usuários, a partir de suas habilidades, preferências e necessidades, sejam essas temporárias ou permanentes.

\section{Referências bibliográficas}

DE MARSICO, M.; LEVIALDI, S. Evaluating web sites: exploiting user's expectations. International Journal of Human-Computer Studies. Volume 60, Issue 3 (March 2004). Incorporating knowledge acquisition. Pages: 381 - 416. ISSN:1071-5819. 2004. Disponível em: <http://www.sciencedirect.com/science?_ob=MImg\&_ imagekey=B6WGR-4BCXJ5K-1 -T\&_cdi=6829\&_user $=972052 \&$ \& orig $=$ search 
\&_coverDate=03\%2F31\%2F2004\&_sk=999399996\&view=c\&wchp=dGLbVtb-zSkWb\& md5=46102f2e695f3b7564594bdcd1a0efa2\&ie=/sdarticle.pdf>. ' em: 09 abr. 2008.

HENRY, Shawn Lawton. WAI Resources on Introducing Web Accessibility. W3C/WAI - World Wide Web Consortium / Web Accessibility Initiative. 2007. Disponível em: <http://www. w3.org/WAI/gettingstarted/Overview.html>. Acesso em 25 fev. 2007.

LIMA-MARQUES, Mamede; MACEDO, Flávia Lacerda Oliveira. Arquitetura da Informaçáo: base para a gestáo do conhecimento. In: TARAPANOFF, Kira (Org.). Inteligência, Informação e Conhecimento. Brasília : IBICT, UNESCO, 2006.

MORVILLE, P.; ROSENFELD, L. Information Architecture for the World Wide Web. 3 Ed., Sebastopol, CA: O'Reilly, 2006.

NEVILE, Liddy. Access For All Accessibility: an inclusive approach. 2007. La Trobe University. OZeWAI 2007. Disponível em: <http://www.slideshare.net/ozewai/afa-liddynevile?src=embed $>$. Acesso em: 13 mar. 2008. 